\title{
Salmonella sp e Listeria monocytogenes em presunto suíno comercializado em supermercados de Fortaleza (CE, Brasil): fator de risco para a saúde pública
}

\author{
Salmonella sp and Listeria monocytogenes in fully cooked ham \\ commercialized in supermarkets of Fortaleza (CE, Brazil): \\ risk factor for public health
}

Ana Elizabeth Cavalcante Fai ${ }^{1}$

Evânia Altina Teixeira de Figueiredo ${ }^{2}$

Sylvia Elisa Frizzo Verdin ${ }^{2}$

Neuma Maria de Souza Pinheiro ${ }^{3}$

Anna Rafaela Cavalcante Braga ${ }^{2}$

Tânia Lúcia Montenegro Stamford ${ }^{4}$

${ }^{1}$ Departamento de Ciências de Alimentos, Faculdade de Engenharia de Alimentos,

Universidade Estadual de Campinas. Av. Monteiro

Lobato 80 , Barão Geraldo. 13083-862. Campinas SP. bethfai@yahoo.com.br

${ }^{2}$ Departamento de Tecnologia de Alimentos,

Universidade Federal do

Ceará.

${ }^{3}$ Departamento de

Tecnologia de Alimentos,

Universidade Federal de

Viçosa (MG).

${ }^{4}$ Departamento de Nutrição,

Universidade Federal de

Pernambuco.

\begin{abstract}
The objective of this work was to evaluate the occurrence of Salmonella sp. and Listeria spp. in fully cooked ham without fat cover, stored under refrigeration, commercialized in supermarkets of Fortaleza (CE, Brazil). Forty samples of cooked ham, proceeding from eight trademarks, collected in 26 establishments, were analyzed according to the APHA and HBP for Salmonella sp. and Listeria spp. detection, respectively. Thirty percent of the samples were contaminated with Salmonella sp. and $42.50 \%$, $22.50 \%$ e $2.5 \%$ with L. monocytogenes, L. innocua $e$ L. welshimeri, respectively. It was also observed imperfections in the application of good manipulation practices in the supermarkets freezer section. It was verify that $34.61 \%, 57.69 \%$ e $15.38 \%$ of the establishments presented some sample contaminated with Salmonella sp., L. monocytogenes and both microorganisms respectively, including the area inspected by the six Regionals Executive General Offices of Fortaleza. These data show the necessity of a quality control improvement in all parts of food systems as an essential factor in the prevention of foodborne diseases.
\end{abstract}

Key words Cooked ham, Salmonella sp., Listeria sp., Supermarkets, Good manipulation practices
Resumo O objetivo deste trabalho foi avaliar a ocorrência de Salmonella sp. e Listeria spp. em presunto suíno cozido sem capa de gordura, mantido sob temperatura de refrigeração, comercializado em supermercados de Fortaleza (CE). O material estudado compreendeu quarenta amostras, provenientes de oito marcas comerciais, coletadas em 26 estabelecimentos. A pesquisa de Salmonella sp. e Listeria spp. foi efetuada segundo APHA e HBP, respectivamente. Foi constatado que $30 \%$ das amostras estavam contaminadas por Salmonella sp. e 42,50\%, 22,50\% e 2,5\% por $\mathrm{L}$. monocytogenes, L. innocua $e$ L. welshimeri, respectivamente. Foram observadas, ainda, falhas na aplicação das boas práticas de manipulação na área de frios dos supermercados. Verificou-se que $34,61 \%, 57,69 \%$ e $15,38 \%$ dos estabelecimentos apresentaram alguma amostra contaminada por Salmonella sp., L. monocytogenes e ambos os microrganismos, respectivamente, abrangendo a área de fiscalização das seis Secretarias Executivas Regionais (SER) do município de Fortaleza. Estes dados mostram a necessidade de um aperfeiçoamento quanto ao controle de qualidade em todo elo da cadeia alimentar como fator fundamental na prevenção de enfermidades transmitidas por alimentos (ETA).

Palavras-chave Presunto cozido, Salmonella sp., Listeria sp., Supermercados, Boas práticas de manipulação 


\section{Introdução}

A crescente demanda de produtos industrializados de conveniência, como minimamente processados, refrigerados e prontos para o consumo, tem contribuído para que o risco de enfermidades transmitidas por alimentos aumente $e^{1-3}$. Dentre as infecções alimentares, a salmonelose é a de maior ocorrência no Brasil e no mundo ${ }^{2,4-9}$; em contraste, a listeriose é menos frequente, contudo apresenta elevada taxa de mortalidade $(20-30 \%)^{10-12}$.

Estima-se que nos Estados Unidos haja uma perda de aproximadamente US\$2 bilhões, por ano, em razão de produtos cárneos contaminados por L. monocytogenes recolhidos do mercado ${ }^{13}$.

Das espécies de Listeria, L. monocytogenes é o principal patógeno para o homem. A natureza ubiquitária, psicrófila, microaerófila e grande resistência a adversidades diferem esta espécie de muitos patógenos alimentares, estando sua emergência diretamente associada às mudanças nos hábitos alimentares dos países industrializados, marcadamente pela cadeia do frio ${ }^{7,14,15}$.

A listeriose caracteriza-se por um quadro de alta severidade (meningite, septicemia, aborto) e natureza não entérica, havendo predileção por indivíduos imunodeprimidos, idosos, neonatos e gestantes ${ }^{10,16}$. Apesar de incomum, existem registros de surtos de listeriose caracterizados por sintomas gastrintestinais envolvendo indivíduos saudáveis ${ }^{14}$. De acordo com Selby et al. ${ }^{17}$, esse quadro pode ocorrer quando elevado número de células de Listeria monocytogenes (> 100 UFC/ g ou $\mathrm{mL}$ ) é ingerido ou quando certos antiácidos e/ou compostos contendo cimetidina são utilizados para sanar úlceras de estômago e azia.

Como tentativa de minimizar a ocorrência de listeriose, em 2001 o Food and Drug Administration (FDA) e o United States Departament of Agriculture (USDA) lançaram o Plano de Ação Listeria com enfoque para derivados de carne e aves prontos para consumo, observando-se em 2004 um decréscimo de surtos de 40\% em comparação a 1996-1998 $8^{18}$.

A salmonelose, por sua vez, é geralmente uma doença autolimitada, apresentando cólicas abdominais, vômito, febre e diarreia, e particularmente em crianças e idosos pode se tornar grave $e^{3}$.

Todas as espécies de Salmonella são patógenas ao homem ${ }^{19,20}$. Nos Estados Unidos e na Europa, esta bactéria é considerada um grave problema de saúde pública, que demandou não apenas a implantação de uma rede network de notificação e informação entre os países sobre o patógeno, com recentes esforços para inclusão dos países da América Latina, como a modificação de seus códigos sanitários ${ }^{21}$.

Ultimamente, observa-se uma preocupação crescente quanto à importância de produtos cárneos derivados de suínos como possíveis veiculadores de Salmonella e Listeria monocytogenes, principalmente aqueles que são consumidos sem nenhum tratamento térmico pós-processamento, tais como o presunto cozido ${ }^{2,22-26}$.

Define-se como presunto cozido o produto elaborado a partir do pernil de suíno sem osso, sem pele, curado em salmoura e cozido em seu pedaço original a $65-75^{\circ} \mathrm{C}$, sendo refrigerado logo após a cocção ${ }^{27,28}$. Caracteriza-se por apresentar mínimo de 14\% de proteína bruta, $\mathrm{pH}$ entre 5,9 e 6,1 e atividade de água na faixa de 0,91 a 0,97, parâmetros que tornam esse produto bastante susceptível à contaminação bacteriana ${ }^{20,27}$.

No Brasil, em especial no Nordeste, poucas são as investigações da qualidade microbiológica de produtos cárneos derivados de suínos disponíveis no comércio. Assim, este trabalho teve por objetivo avaliar a presença de Salmonella sp. e Listeria spp. em presunto suíno cozido, sem capa de gordura, comercializado sob temperatura de refrigeração, bem como verificar as boas práticas na área de frios dos supermercados ${ }^{29}$.

\section{Materiais e métodos}

Este estudo foi desenvolvido de setembro a dezembro de 2005, quando foram adquiridas quarenta amostras de presunto suíno cozido sem capa de gordura, de oito diferentes marcas comercializadas sob temperatura de refrigeração, em 26 supermercados pertencentes às seis Secretarias Executivas Regionais (SER) do município de Fortaleza (CE). Todas as amostras possuíam registro no Serviço de Inspeção Federal (SIF) do Ministério da Agricultura, Pecuária e Abastecimento. Os presuntos foram fatiados no ato de aquisição e embalados em bandejas de poliestireno cobertas por filme de PVC. As amostras foram, então, acondicionadas em caixas isotérmicas contendo baterias de gelo conservador e transportadas em seguida para o Laboratório de Microbiologia de Alimentos do Departamento de Tecnologia de Alimentos da Universidade Federal do Ceará, onde foram imediatamente analisadas.

A pesquisa de Salmonella sp. foi efetuada pelo método tradicional ${ }^{30}$, e o isolamento de Listeria spp., bem como sua identificação fenotípica e bioquímica, foi realizado segundo metodologia proposta por Farber et al. ${ }^{31}$ e Farber e Daley ${ }^{32}$. 


\section{Resultados e discussão}

Conforme observado na Tabela 1, evidenciou-se que $30 \%$ das amostras apresentaram positividade para Salmonella sp. em 25g, estando em desacordo com as diretrizes estabelecidas na RDC $n^{\circ}$ 12 da Agência Nacional de Vigilância Sanitária ${ }^{29}$.

Várias publicações fazem referência às ocorrências de surtos de infecções alimentares por Salmonella em produtos cárneos ${ }^{1,2,8,33-35}$. De acordo com Fortuna e Franco ${ }^{36}$, a presença de salmonela em amostras de carne armazenadas a $0^{\circ}$ $\mathrm{C} \mathrm{e}-18^{\circ} \mathrm{C}$ por noventa dias indica que essas bactérias sobrevivem a períodos longos de armazenamento, mesmo em baixas temperaturas.

Não obstante o elevado índice de amostras contaminadas por Listeria monocytogenes constatado nesta pesquisa, não existem padrões oficiais brasileiros em relação à disseminação deste patógeno em carnes e produtos cárneos. Este resultado é comparável ao descrito por outros autores para alimentos prontos para o consumo refrigerados ${ }^{16,37-41}$. Tais considerações demonstram a necessidade de um rastreamento maior em nível nacional da presença dessa bactéria em alimentos prontos para o consumo que subsidi- em os órgãos de saúde pública responsáveis a definirem critérios e padrões microbiológicos para Listeria monocytogenes nesse tipo de produto.

Considerando que o processo de cozimento do presunto é suficiente para destruir Listeria monocytogenes, bem como Salmonella, a contaminação desse alimento ocorre em etapas pósprocessamento ou resulta de subprocessamento. A presença desses gêneros pode ser atribuída ainda a contaminações cruzadas durante manuseio e fatiamento.

Nadvorny et al. ${ }^{5}$, analisando a ocorrência de 99 surtos de salmonelose transmitida por alimentos ocorridas no Rio Grande do Sul no ano de 2000 , observaram que em $73 \%$ a manipulação incorreta dos alimentos constituiu-se em fator predisponente à contaminação por Salmonella.

Araújo et al. ${ }^{38}$ analisaram quarenta amostras de carne de peru, divididas em quatro grupos de dez: blanquet inteiro, blanquet fatiado, presunto inteiro e presunto fatiado, verificando uma alta incidência de bactérias do gênero Listeria, da ordem de $80 \%$ em blanquet e de $90 \%$ em presunto, contrastando com a ausência nos inteiros. A ausência de Listeria nos produtos inteiros e sua alta ocorrência nos fatiados sugerem provável manipula-

Tabela 1. Avaliação microbiológica de presunto suíno cozido comercializado em supermercados de Fortaleza (CE) durante os meses de setembro a dezembro de 2005.

\begin{tabular}{|c|c|c|c|c|c|}
\hline Origem & Listeria (25g) & Salmonella sp. (25g) & Origem & Listeria (25g) & Salmonella sp. (25g) \\
\hline $\mathrm{A} \mathrm{I}_{2}$ & L. monocytogenes & Ausência & $\mathrm{D} \mathrm{II}_{11}$ & L. monocytogenes & Ausência \\
\hline $\mathrm{A} \mathrm{II}_{13}$ & L. monocytogenes & Ausência & D III $_{21}$ & L. innocua & Ausência \\
\hline A III ${ }_{18}$ & Ausência & Ausência & $\mathrm{D} \mathrm{IV}_{23}$ & L.innocua & Ausência \\
\hline $\mathrm{A} \mathrm{IV}_{26}$ & Ausência & Presença & $\mathrm{E} \mathrm{I}_{1}$ & Ausência & Presença \\
\hline $\mathrm{B} \mathrm{I}_{2}$ & L. innocua & Ausência & $\mathrm{E} \mathrm{II}_{3}$ & L. monocytogenes & Ausência \\
\hline $\mathrm{B} \mathrm{II}_{5}$ & Ausência & Ausência & $\mathrm{E} \mathrm{III}_{5}$ & L. monocytogenes & Ausência \\
\hline $\mathrm{B} \mathrm{III}_{7}$ & Ausência & Ausência & $\mathrm{E} \mathrm{IV}_{20}$ & Ausência & Ausência \\
\hline $\mathrm{B}_{\mathrm{IV}}$ & L. monocytogenes & Ausência & $\mathrm{FI}_{3}$ & L. innocua & Ausência \\
\hline $\mathrm{B} \mathrm{V}_{16}$ & L. monocytogenes & Presença & $\mathrm{F} \mathrm{II}_{7}$ & L. inпосиа & Ausência \\
\hline $\mathrm{B} \mathrm{VI}_{21}$ & Ausência & Ausência & $\mathrm{F} \mathrm{III}{ }_{9}$ & Ausência & Ausência \\
\hline $\mathrm{B} \mathrm{VII}_{23}$ & L. innocua & Ausência & F III ${ }_{10}$ & Ausência & Ausência \\
\hline B VIII $_{24}$ & L. innocua & Ausência & F IV & L. monocytogenes & Presença \\
\hline $\mathrm{C} \mathrm{I}_{8}$ & L. monocytogenes & Ausência & $\mathrm{G} \mathrm{I}_{4}$ & L. welshimeri & Ausência \\
\hline $\mathrm{C} \mathrm{II}_{12}$ & L. monocytogenes & Presença & $\mathrm{G} \mathrm{II}_{6}{ }_{6}$ & L. monocytogenes & Ausência \\
\hline $\mathrm{C} \mathrm{III}_{14}$ & L. monocytogenes & Presença & G III $_{16}$ & L. monocytogenes & Presença \\
\hline $\mathrm{C} \mathrm{IV}_{15}$ & Ausência & Presença & $\mathrm{G} \mathrm{IV}_{25}$ & L. inпосиа & Ausência \\
\hline $\mathrm{C} \mathrm{V}_{18}$ & L. monocytogenes & Presença & $\mathrm{H} \mathrm{I}_{4}$ & Ausência & Ausência \\
\hline $\mathrm{C} \mathrm{VI}_{22}$ & L. monocytogenes & Ausência & $\mathrm{H} \mathrm{II}_{12}$ & L. monocytogenes & Presença \\
\hline $\mathrm{C} \mathrm{VII}_{24}$ & L. innocua & Ausência & $\mathrm{H} \mathrm{III}_{17}$ & Ausência & Presença \\
\hline $\mathrm{D} \mathrm{I}_{1}$ & Ausência & Presença & $\mathrm{H} \mathrm{IV}_{25}$ & L. monocytogenes & Ausência \\
\hline
\end{tabular}

Origem: a letra corresponde ao produtor, à numeração romana à amostra do mesmo produtor e o algarismo ao supermercado em que a amostra foi adquirida. 
ção inadequada dos produtos no momento do fatiamento, o que implica necessidade de melhorar o controle higiênico durante o processamento.

A área de frios dos supermercados, onde as amostras de presuntos foram adquiridas, pode ser considerada um ambiente crítico devido à deficiência na aplicação de boas práticas de manipulação, tomando como parâmetros de qualidade as exigências legais estabelecidas na Portaria ${ }^{\circ}$ 326 e na RDC no 216 do Ministério da Saúde ${ }^{42,43}$.

Verificou-se a exposição de produtos crus e cozidos na mesma vitrine; presença de resíduos em equipamentos e utensílios; ausência de lavatório exclusivo para lavagem de mãos e manipuladores que realizavam diversas atividades e manuseavam alimentos crus e prontos para o consumo com a mesma luva. Constataram-se ainda a ocorrência de falhas na conservação do presunto mediante abusos de temperatura e a eficácia dos procedimentos operacionais de higienização de recipientes, bandejas, tábuas, bancadas e principalmente da máquina fatiadora.

Muniz et al. ${ }^{44}$ observaram através de microscopia a formação de biofilmes em amostras de presuntos fatiados, relatando a presença de substâncias mucilaginosas e grande diversidade microbiana, contaminação atribuída ao processo de fatiamento. Ressalte-se que microrganismos em biofilme são consideravelmente mais resistentes à remoção por agentes de sanificação, uma vez que estes estão protegidos pela matriz do biofilme $e^{20}$. Tal fato é preocupante, uma vez que o presunto é consumido sem nenhum tratamento térmico pós-processamento que possa reduzir o número da microbiota presente. Além do mais, nas embalagens de fatiados reúne-se uma série de fatores críticos: pequenas porções que implicam maior relação área embalagem/peso produto e uma grande área exposta do produto devido ao fatiamento ${ }^{45}$. Por conseguinte, este produto é mais suscetível à contaminação pelo ar, à retenção de umidade relativa e, consequentemente, ao aumento da atividade de água, facilitando dessa maneira a multiplicação bacteriana ${ }^{46}$. Tais fatores, aliados à deficiência das boas práticas de manipulação e às características intrínsecas do presunto, tendem a reduzir a vida de prateleira deste produto, comprometendo a satisfação do consumidor e acarretando perdas econômicas, tornando-se um risco ao consumidor.

Observou-se a ocorrência de amostras contaminadas em supermercados de todas as Secre- tarias Executivas Regionais (SER) do município de Fortaleza. Verificou-se que $34,61 \%$ e $57,69 \%$ dos estabelecimentos (Tabela 1) apresentaram alguma amostra contaminada por Salmonella sp. e L. monocytogenes, respectivamente, e em 15,38\% constataram-se ambos os microrganismos, indicando que as falhas de boas práticas de manipulação ocorrem em bairros nobres e na periferia.

A presença de Listeria monocytogenes em presunto é um fator de risco principalmente para imunocomprometidos, gestantes e idosos, estando estes últimos em ascensão na taxa de incidência de listeriose humana.

Recomendam-se algumas alterações na legislação, tais como a obrigatoriedade de contratação de um profissional capacitado na área de alimentos em supermercados. Além do mais, caberia à Vigilância Sanitária não apenas o papel de fiscalizar, mas também de atuar como multiplicador das boas práticas higiênico-sanitárias mediante atividades educativas permanentes dirigidas aos consumidores, alertando para os riscos representados pela manipulação inadequada ${ }^{47}$.

Embora a escassez de dados dificulte comparações, situações semelhantes às encontradas neste trabalho podem estar ocorrendo em muitas outras cidades brasileiras, exigindo medidas enérgicas de intervenção por parte dos órgãos de saúde pública responsáveis.

Os dados apontados neste estudo podem contribuir para a discussão da importância da implementação de sistemas de gerenciamento de qualidade e para alertar e acentuar as exigências dos órgãos de saúde pública e dos consumidores para os controles que afetam a sanidade dos alimentos de forma geral.

\section{Conclusões}

Considerando o processo de cozimento do presunto e que as amostras analisadas neste estudo foram fatiadas nos supermercados, atribuiu-se, em princípio, a ocorrência de Listeria monocytogenes e Salmonella sp. ao não cumprimento das boas práticas de manipulação na área de frios desses estabelecimentos. Ressalta-se a necessidade de uma fiscalização mais rigorosa e da efetiva implementação de programas de controle de qualidade que garantam a oferta de alimentos prontos para o consumo seguros à saúde do consumidor. 


\section{Colaboradores}

AEC Fai foi responsável pela análise, interpretação dos dados e redação do artigo; EAT Figueiredo, pela concepção e pelo delineamento, interpretação dos dados e revisão crítica; SEF Verdin, pela concepção e pelo delineamento e análise; NMS Pinheiro e ARC Braga, pela análise dos dados; e TLM Stamford, pela revisão crítica do artigo.

\section{Referências}

1. McCormick KE, Han IY, Acton JC, Sheldon BW, Dawson PL. In-package pasteurization combined with biocideimpregnated films to inhibit Listeria monocytogenes and Salmonella typhimurium in Turkey Bologna. Journal of Food Science 2005; 70(1):5257.

2. Mehrabian S, Jaberi E. Isolation, identification and antimicrobial resistence patterns of Salmonella from meat products in Tehran. Pakistan Journal of Biological Sciences 2007; 10(11):122-126.

3. Samuel CM, Vugia DJ, Koehler KM, Marcus R, Dennen V, Damaske B, Shiferaw B, Hadler J, Henao OL, Angulo FJ. Consumption of risky foods among adults at high risk for severe foodborne diseases: room for improved targeted prevention messages. Journal of Food Safety 2007; 27:219-232.

4. Bessa MC, Costa M, Cardoso M. Prevalência de Salmonella sp. em suínos abatidos em frigoríficos no Rio Grande do Sul. Pesq Vet Bras 2004; 24(2):80-84.

5. Nadvorny A, Figueiredo DMS, Schmidt V. Ocorrência de Salmonella sp. em surtos de doenças transmitidas por alimentos no Rio Grande do Sul em 2000. Acta Scientiae Veterinariae 2004; 32(1):47-51.

6. Carvalho ACFB, Cortez ALL. Salmonella spp. em carcaças, carne mecanicamente separada, lingüiças e cortes comerciais de frango. Ciência Rural 2005; 35(6):1465-1468.

7. Jofré A, Martin B, Guarriga M, Hugas M, Pla M, Rodríguez-Lázaro D, Aymerich T. Simultaneous detection of Listeria monocytogenes and Salmonella by multiplex PCR in cooked ham. Food Microbiology 2005; 22:109-115.

8. Gibbons IA, Adesiyun A, Seepersadsingh N, Rahaman S. Investigation for possible source(s) of contamination of ready-to-eat meat products with Listeria spp. and other pathogens in a meat processing plant in Trinidad. Food Microbiology 2006; 23:359-366.

9. Francisco DC, Nascimento VP, Loguercio AP, Camargo L. Caracterização do consumidor de carne de frango em Porto Alegre. Ciência Rural 2007; 37(1):253-258.

10. Barros MAF, Nero LA, Silva LCS, D’Ovidio L, Monteiro FA, Tamanini R, Fagnani R, Hofer E, Beloti V. Listeria monocytogenes: occurrence in beef and identification of the main contamination points in processing plants. Meat Science 2007; 76:591-596.
11. Jofré A, Garriga M, Aymerich T. Inhibition of Salmonella sp., Listeria monocytogenes and Staphylococcus aureus in cooked ham by combining antimicrobials, high hydrostatic pressure and refrigeration. Meat Science 2007; doi: 10.1016/j.meatsci.2007. 06.015

12. Nufer U, Stephan R, Tasara T. Growth characteristics of Listeria monocytogenes, Listeria welshimeri and Listeria innocua strains in broth cultures and a sliced bologna-type product at 4 and $71^{\circ} \mathrm{C}$. Food Microbiology 2007; 24:444-451.

13. Luchansky JB, Call JE, Hristova B, Rumery L, Yoder L, Oser A. Viability of Listeria monocytogenes on commercially-prepared hams surface treated with acidic calcium sulfate and lauric arginate and stored at $4 \mathrm{C}^{\circ}$. Meat Science 2005; 71:92-99.

14. Branco MAAC, Figueiredo EATF, Borges MF, Silva MCD, Destro MT. Incidência de Listeria monocytogenes em queijo de coalho refrigerado produzido industrialmente. Boletim do Ceppa 2003; 21(2):393408.

15. Ichiro Sakate R, Aragon LC, Raghiante F, Landgraf M, Franco DGM, Destro MT. Quantificação de Listeria monocytogenes em salames fatiados embalados a vácuo. Archivos Latinoamericanos de Nutrición 2003; 53(2):184-187.

16. Gandhi M, Chikindas ML. Listeria: a foodborne pathogen that knows how to survive. International Journal of Food Microbiology 2007; 113:1-15.

17. Selby TL, Berzins A, Gerrard DE, Corvalan CM, Grant AL, Linton RH. Microbial heat resistance of Listeria monocytogenes and the impact on ready-toeat meat quality after post-package pasteurization. Meat Science 2006; 74:425-434.

18. Centers for Disease Control and Prevention (CDC). Preliminary FoodNet Data on the Incidence of Infection with Pathogens Transmitted Commonly Through Food - 10 Sites, United States, 2004. Morbidity and Mortality Weekly Report [periódico na internet]. abr 2005 [acessado 2007 set 17]; 54(14): [cerca de 4p]. Disponível em: http://www.cdc.gov/ $\mathrm{mmwr} /$ preview/mmwrhtml/mm5414a2.htm

19. Forsythe SJ. Microbiologia da segurança alimentar. Porto Alegre: Artmed; 2002.

20. Jay JM. Microbiologia de alimentos. Porto Alegre: Artmed; 2005. 
21. Divisão de Doenças de Transmissão Hídrica e Alimentar/Centro de Vigilância Epidemiológica (DDTHA/CVE). Salmonella enteritidis: uma importante causa de surtos bacterianos veiculados por alimentos e a necessidade de uma nova regulamentação sanitária para os alimentos implicados, São Paulo, Brasil, 1999-2003. Boletim Epidemiológico Paulista 2004; 8(1):6-10.

22. Salvatori RU, Bessa MC, Cardoso MRI. Qualidade sanitária de embutidos coletados no mercado público central de Porto Alegre-RS. Ciência Rural 2003; 33(4):771-773.

23. Fortuna JL, Franco RM. Uma revisão epidemiológica das principais alterações microbiológicas em produtos cárneos embutidos. Revista Higiene Alimentar 2005; 19(129):35-42.

24. Jo C, Lee NY, Kang H, Hong S-P, Kim Y-H, Kim HJ, Byun MW. Radio-sensitivity of pathogens in inoculated prepared foods of animal origin. Food Microbiology 2005; 22:329-336.

25. Li Y, Zhuang S, Mustapha A. Application of a multiplex PCR for the simultaneous detection of Escherichia coli O157:H7, Salmonella and Shigella in raw and ready-to-eat meat products. Meat Science 2005; 71:402-406.

26. Mottin VD, Fish E, Mürmann L, Cardoso MI. Pesquisa de Listeria monocytogenes e Salmonella sp. em embutidos de carne suína cozidos e fatiados comercializados em supermercados no município de Porto Alegre, RS. Revista Higiene Alimentar 2006; 21(150):191-192.

27. Brasil. Ministério da Agricultura e do Abastecimento. Secretaria de Defesa Agopecuária. Instrução Normativa no 20, de 31 de julho de 2000. Regulamento Técnico de Identidade e Qualidade de Almôndega, de Apresuntado, de Fiambre, de Hamburguer, de Kibe, de Presunto Cozido e de Presunto. Diário Oficial da União 2000; 31 jul.

28. Ordoñez JÁ, Rodríguez MIC, Álvarez LF, Sanz MLG, Minguillón GDGF, Perales LH, Cortecero MDS. Tecnologia de alimentos. v. 2. Porto Alegre: Artmed; 2005.

29. Brasil. Agência Nacional de Vigilância Sanitária (Anvisa). RDC no 12, de 2 de janeiro de 2001. Regulamento Técnico sobre Padrões Microbiológicos para Alimentos. Diário Oficial da União 2001; 2 jan.

30. Vanderzant C, Splittstoesser DF. Compendium of methods for the microbiological examination of food. $3^{\text {rd }}$ ed. Washington: American Public Health Association; 1992.

31. Farber JM, Warburton DW, Babiuk T. Isolation of Listeria monocytogenes from all food and environmental samples. In: Government of Canada. HBP method. Quebec (Canadá): Polyscience Publications; 1994.

32. Farber JM, Daley E. Enumeration of Listeria monocytogenes in food - Government of Canada - Laboratory procedure. Quebec (Canadá): Polyscience; 1995.

33. Barros VRM, Pavia PC, Panetta JC. Salmonella spp.: sua transmissão através dos alimentos. Revista Higiene Alimentar 2002; 16(94):15-19.

34. O’Bryan CA, Crandall PG, Martin EM, Griffis CL, Johnson MG. Heat resistance of Salmonella spp., Listeria monocytogenes, Escherichia coli 0157:H7, and Listeria innocua M1, a potential surrogate for Listeria monocytogenes, in meat and poultry: a review. Journal of Food Science 2006; 71(3):23-30.
35. Centro de Vigilância Epidemiológica (CVE). Uma revista eletrônica de epidemiologia das doenças transmitidas por alimentos. Rev Net - Dta [periódico na Internet]. 2002 [acessado 2007 set 18]; 2(5): [cerca de 18p]. Disponível em: ftp://ftp.cve.saude.sp.gov.br/ doc_tec/hidrica/revp02_vol2n5.pdf

36. Fortuna JL, Franco RM. Pequeno dossiê epidemiológico da Salmonella como causadora de infecções alimentares. Revista Higiene Alimentar 2005; 19(128):33-44.

37. Guerra MM, McLauchlin J, Bernardo FA. Listeria in ready-to-eat and unprocessed foods produced in Portugal. Food Microbiology 2001; 18:423-429.

38. Araújo PCC, Franco RM, Oliveira LAT, Carvalho JCAP. Ocorrência de Listeria monocytogenes em produtos de carne de peru comercializados na cidade de Niterói-RJ-Brasil. Acta Scientiae Veterinariae 2002; 30(1):19-25.

39. McCormick K, Han IY, Acton JC, Sheldon BW, Dawson PL. D- and $z$-values for Listeria monocytogenes and Salmonella typhimurium in packaged lowfat ready-to-eat turkey bologna subjected to a surface pasteurization treatment. Poultry Science 2003; 82:1337-1342.

40. Mena C, Almeida G, Carneiro L, Teixeira P, Hogga $\mathrm{T}$, Gibbs PA. Incidence of Listeria monocytogenes in different food products commercialized in Portugal. Food Microbiology 2004; 21:213-216.

41. Degenhardt R, Sant'Anna ES. Pesquisa de Listeria sp. em embutidos cárneos fermentados produzidos na região Meio-Oeste de Santa Catarina, Brasil. Boletim do Ceppa 2007; 25(1):133-140.

42. Brasil. Portaria no 326, de 30 de julho de 1997. Regulamento Técnico sobre Condições HigiênicoSanitárias e de Boas Práticas de Fabricação para Estabelecimentos Produtores/Industrializadores de Alimentos. Diário Oficial da União 1997; 30 jul.

43. Brasil. Portaria no 216, de 15 de setembro de 2004 . Regulamento Técnico sobre Condições HigiênicoSanitárias e de Boas Práticas para Serviços de Alimentação. Diário Oficial da União 2004; 15 set.

44. Muniz CR, Rabelo JL, Freitas CAS, Sério J, Dodou HD. Observação microscópica de biofilmes em amostras de presuntos fatiados refrigerados comercializados em supermercados de Fortaleza, Ceará. Rev Higiene Alimentar 2007; 21(150):97-98.

45. Sarantópoulos CIGL, Oliveira LM, Antonio JT. Propriedades de embalagens e sua influência na qualidade de produtos cárneos. Rev Nacional da Carne, Grupo Dipemar [periódico na Internet]. jul 2003 [acessado 2006 maio 17]; 317: [cerca de 4p.]. Disponível em: http://www.dipemar.com.br/CARNE/ 317/materia_embalagens2_carne. htm

46. Bressan MC, Lodi F, Ferreira MW, Andrade PL, Boaris A, Piccoli RH. Influência da embalagem na vida útil de presuntos fatiados. Ciên Agrotec 2007; 31(2):433-438.

47. Valente D, Passos ADC. Avaliação higiênico-sanitária e físico-estrutural dos supermercados de uma cidade do Sudeste do Brasil. Revista Brasileira de Epidemiologia 2004; 7(1):80-87.

Artigo apresentado em 03/10/2007

Aprovado em 17/07/2008

Versão final apresentada em 06/08/2008 